\title{
Synapse disassembly
}

\author{
Benjamin A. Eaton and Graeme W. Davis ${ }^{1}$ \\ Department of Biochemistry and Biophysics, University of California, San Francisco, \\ San Francisco, California 94143-0448, USA
}

The transfer of information between cells in the nervous system is mediated, primarily, through synaptic connections. A synapse is an intercellular junction defined ultrastructurally as a postsynaptic electron density (PSD) in direct opposition to a presynaptic density associated with clustered synaptic vesicles that is referred to as an active zone. The synaptic cleft is a tight, stable intercellular junction that is resistant to biochemical disruption. The intervening space at the synapse is termed the synaptic cleft and includes extrasynaptic material that has been best defined at the mammalian neuromuscular junction (NMJ) where it is continuous with the basal lamina. Synaptic vesicles released presynaptically are in direct opposition to the postsynaptic neurotransmitter receptors that are activated upon binding ligand. A synapse, thus, is defined as a single active zone and associated postsynaptic specialization. In many cases, multiple synapses connect two cells as at the neuromuscular junction where the ensemble of synapses can be referred to as a synaptic input or junction.

We are rapidly moving toward a complete biochemical description of the proteins that constitute the mammalian glutamatergic synapse that predominates the central nervous system and the vertebrate NMJ that uses acetylcholine as a neurotransmitter (Sanes and Lichtman 1999; Sheng and Lee 2000; Walikonis et al. 2000). The emerging picture of the synapse is of a large, macromolecular complex that spans the cleft between the two connected neurons (or neuron and muscle). This large macromolecular complex is capable of coupling the influx of calcium driven by a nerve impulse (action potential) to the probabilistic release of single vesicles of neurotransmitter. Though only a portion of the proteins at the active zone are essential for the release of synaptic vesicles, many scaffolding and signaling proteins that localize to the active zone are implicated in the modulation or plasticity of the active zone (Sheng and Kim 2002).

A remarkable feature of synaptic connections is that they are dynamic. Individual synapses can be stable for prolonged periods of time, which is presumably necessary for the stable function of neural circuits, but syn-

${ }^{1}$ Corresponding author.

E-MAIL gdavis@biochem.ucsf.edu; FAX (415) 502-5145.

Article and publication are at http://www.genesdev.org/cgi/doi/10.1101/ gad.1113703. apses also retain the capacity to be rapidly disassembled and reformed. The formation of new synaptic connections and the elimination of previously functional synaptic connections are particularly prominent during early development, but these processes also continue throughout the lifetime of an animal (Purves and Lichtman 1980). The dynamic restructuring of connections between neurons is essential for the initial wiring of specific neural circuits and may be an essential process during the continued modification of neural circuits in response to a changing environment or during the cellular processes that underlie learning and memory. A particularly well-studied example is the remodeling of highly ramified retinal projections within the visual cortex resulting in the formation of eye-specific dominance columns.

Considerable progress is being made examining the dynamic nature of synaptic connections. Recent advances in live-imaging technologies have allowed time-lapse imaging of synapse morphology and, in some cases, correlated changes in synaptic function (Yuste and Bonhoeffer 2001; Cohen-Cory 2002). At the molecular level, we are gaining an increasingly detailed view of the mechanisms of synapse assembly. Synaptogenesis requires inductive, intercellular signaling events between the preand postsynaptic partners that lead to the clustering of synaptic molecules and their precise apposition at the pre- and postsynaptic membranes (Sanes and Lichtman 1999; Luo 2000; Scheiffele 2003).

Although considerable attention has been focused on the mechanisms of synaptogenesis, relatively little is understood about the mechanisms that control the regulated disassembly of a previously functional synaptic connection. When considering the mechanisms of synaptic remodeling, the elimination of a synaptic connection between two cells is a dramatic event and is one that must also be highly regulated. The significance of regulated synapse disassembly is suggested by recent, in vivo, live-imaging studies. Postsynaptic dendritic spines, which may reflect functional synaptic connections, turnover continually with $5 \%-30 \%$ of spines in an individual neuron within the brain of a mouse being remodeled over the course of 3-4 wk (Grutzendler et al. 2002; Trachtenberg et al. 2002). Extrapolated over the lifetime of the animal, this suggests that potentially $\sim 50 \%$ of all spines might be remodeled at some point during a lifetime. If changes in spine morphology reflect the forma- 
tion and elimination of individual active zones, then the regulated disassembly of synapses is a prominent process and one that must be regulated and balanced with the mechanisms of synaptogenesis. Here we review the literature, phenomenology, and mechanisms of synapse disassembly.

\section{Synapse elimination during neural development}

Synapse disassembly can modify the strength of the connectivity between two cells and may participate in the mechanisms of synaptic plasticity (Bailey and Kandel 1993; Lichtman and Colman 2000). In the more extreme examples, synapse disassembly can lead to the complete elimination of synaptic connectivity between two cells, which is referred to as "input elimination." Although all input elimination events necessarily involve synapse disassembly, not all synaptic disassembly events lead to the elimination of an input. It should also be noted that synapse disassembly has been observed in neurons during periods in which input elimination is known to occur, suggesting that these processes can coexist within the same cell (Cline 2001). Despite this intimate relationship between synapse disassembly and input elimination, it is unclear at this point whether these processes are governed by similar molecular processes or are fundamentally different.

Input elimination has been observed in many parts of the nervous system, including the visual system, auditory system, cerebellum, autonomic ganglia, and skeletal muscle, where the number of inputs declines during critical periods early in development (Purves and Lichtman 1980). Even in cases where mature target cells are innervated by more than one presynaptic partner, such as the sympathetic ganglion, the number of innervating axons declines significantly during development (Lichtman and Purves 1980). In addition, input elimination also occurs during the extensive neuronal remodeling observed during metamorphosis in many invertebrate systems (Lee et al. 2000). Thus, the reduction of inputs via elimination appears to be an essential aspect of the normal development of many different neural circuits in both vertebrates and invertebrates and may indicate a conserved process of synaptic disassembly.

In many of the well-studied examples of input elimination, synapse disassembly appears to be a consequence of activity-dependent competition between multiple inputs contacting a single target. However, synaptic competition is not necessary to drive input elimination or synapse disassembly. For example, the elimination of inputs during metamorphosis in insects appears to be governed by hormones rather than activity-dependent competition (Lee et al. 2000). In addition, synapse disassembly appears to be a normal process associated with the growth of the Drosophila NMJ where synaptic competition does not occur. Thus, the mechanisms of synapse disassembly may be separable from the process of synaptic competition. In this scenario, diverse processes ranging from growth to activity-dependent competition and synaptic plasticity could govern a conserved mecha- nism of synapse disassembly. A goal for the future may be to define the common mechanisms of synapse disassembly and elucidate how growth, competition, and plasticity regulate this mechanism.

\section{The mammalian NMJ}

The mammalian NMJ is perhaps the most well-characterized synapse in mammals. At birth, the muscle fiber is innervated by multiple motorneurons, which are gradually eliminated over the course of several of weeks (Sanes and Lichtman 1999). Concurrently, contacts not being eliminated are expanded and differentiated into mature endplates. This brings up an interesting problem of how the correct input is selected for maintenance at the same time that others are selected for synapse disassembly and elimination.

The classic model of selection involves an activitydependent competition between equivalent inputs in which one of the inputs emerges victorious at the expense of the others, which are subsequently eliminated. The involvement of activity was clearly demonstrated in several experiments. If activity is blocked, selection does not occur (Balice-Gordon and Lichtman 1994; but see Costanzo et al. 2000). Several classic experiments also indicate that selection is mediated through the muscle cell. If two motorneuron inputs are separated by enough distance on the muscle surface, both can be maintained (Kuffler et al. 1977). Experiments using focal blockade of postsynaptic receptors further support this view. In these experiments it was shown that focal blockage of receptor activation within a small region of the NMJ induced elimination at these sites suggesting that local differences in receptor activation can drive elimination (Balice-Gordon and Lichtman 1994). These observations have led to the following theories of competition at the NMJ where input elimination is driven by 1) the production of limiting amounts of muscle-derived trophic signals which are more effective at sustaining active inputs; 2) the secretion of muscle-derived "synaptotoxins," which promote the withdrawal of less active inputs; or 3) the generation of a "punishing signal" at the most active contact that would attack competing axons leading to their withdrawal (Sanes and Lichtman 1999).

Recent experiments suggest that there is added complexity to mechanisms that select which input will be disassembled versus maintained. The advent of GFP mice has allowed the time-lapse visualization of the motorneuron terminal in combination with receptor visualization using sub-blocking concentrations of labeled $\alpha$-bungarotoxin. In recent experiments, it was demonstrated that an input could initially begin the process of elimination and then subsequently reverse this process by growing to become the single input that is maintained (Walsh and Lichtman 2003). This observation is important for several reasons. First, it demonstrates that the mechanisms underlying synapse disassembly are reversible. This suggests that elimination is not a switch but is continually driven until the input is ultimately eliminated. Second, this result also indicates that selection for 
elimination involves more than simply receptor activation. Focal blockade experiments demonstrated that reduction in receptor activation led to elimination (BaliceGordon and Lichtman 1994). But in the situation in which elimination is reversed, only a small portion of the receptor field is being activated prior to the reversal event. Thus, there may be other contributing processes that can, in some cases, overcome the muscle-mediated mechanisms of synapse elimination. For example, there may be intrinsic difference between motorneurons that converge on a single muscle that contribute to selection. Mechanisms such as cell-specific surface recognition molecules or neuron-specific programs of activity could act to specify motorneurons. Although specification of cellular identity via protein expression has not been demonstrated at the vertebrate NMJ, two recent reports have demonstrated that pools of motorneurons have diverse activity patterns during periods of synapse elimination (Personius and Balice-Gordon 2001; Buffelli et al. 2002). These authors show that the activity patterns of motorneurons are highly correlated early in development but become uncorrelated by the onset of synapse elimination, suggesting a role for asynchronous firing patterns in synapse elimination. Earlier studies also support the idea that differences in activity can affect the outcome of competition (Duxson and Vrbova 1985; Thompson 1985; Barry and Ribchester 1995). Therefore, intrinsic differences in firing patterns between motorneurons could play an important role in specifying synapse formation and elimination. In addition, it has been reported that there exist intrinsic differences between muscle fibers that affect both assembly and disassembly of NMJs in young adult mice (Pun et al. 2002). These data demonstrate that intrinsic differences may exist between motorneurons and between muscles, which could directly regulate the process of elimination.

Although the molecular identification of trophic factors, synaptotoxins, or punishing signals has remained elusive, it was recently shown that neurotrophin-4 (NT4) is produced by slow muscle fibers in an activity-dependent manner and that production of NT-4 promotes growth and remodeling of the adult NMJ (Belluardo et al. 2001). This raises the interesting possibility that intrinsic changes in presynaptic activity could initiate musclemediated elimination programs such as the release of trophic factors.

\section{The cerebellum}

Purkinje cells (PCs) within the cerebellum receive distinct excitatory inputs from parallel inputs (PFs) and climbing fibers (CFs). During early postnatal development in the rodent brain, PCs are multiply innervated by three to four CFs, which are removed over the course of a few weeks until only one CF axon innervates a single PC (Sotelo 1975; Ito 1984; Mason and Gregory 1984; Mason et al. 1990). The one-to-one relationship between CF and PC is then maintained throughout the lifetime of the adult.

The cerebellum has long been considered a site for motor control and is thought to facilitate the type of discrete motor learning associated with the application of simple movements to more coordinated acts (Thach et al. 1992). Work on mutant mice over the last 25 years has suggested that the failure to properly eliminate supernumerary connections in the cerebellum has functional consequences for the animal. Initial studies on the classic mouse mutants, weaver and staggerer, found that these mutants with obvious motor ataxia also had multiple CFs innervating single PCs in the adult brain (Crepel and Mariani 1976; Crepel et al. 1980). Recent work on mutant mice deficient in PKC, mGluR1, PLC, or $\mathrm{G}_{\alpha \mathrm{q}}$ have also shown a correlation between locomotor ataxia and the failure to properly eliminate $\mathrm{CF}$ innervation on the PCs (Aiba et al. 1994; Conquet et al. 1994; Chen et al. 1995; Kano et al. 1995, 1997; Kim et al. 1997; Offermanns et al. 1997; Ichise et al. 2000). In addition, mutants in mGluR1 are also deficient in Purkinje cell longterm depression (LTD), providing a link between synapse elimination, plasticity, and motor coordination (Ichise et al. 2000).

Because mGluR1 is expressed in other regions of the brain, Ichise and colleagues (2000) performed PC-specific rescue in mGluR1 $1^{-/}$mice to conclusively show that mGluR 1 is required in the postsynaptic PCs for normal regression of multiple CF innervation. Therefore, it is likely that regulation of PLC and PKC via mGluR1 activation is occurring in the postsynaptic cell, which then drives the removal of supernumerary presynaptic connections via the initiation of an unknown elimination program. Although it remains unclear what the mechanisms are leading to the disassembly of synaptic connections between the CFs and PCs, the postsynaptic cell appears to mediate the elimination of presynaptic inputs in the cerebellum, similar to what has been seen at the NMJ.

\section{Elimination in the absence of competition}

Unlike the mammalian cerebellum and NMJ, the Drosophila larval NMJ is molecularly specified such that each muscle cell receives input from identified motorneurons and these inputs persist throughout development (Keshishian et al. 1996). Though the number of innervating axons doesn't change during larval development, the size of the synapse increases dramatically as the animal increases in size nearly 20 -fold. This is due to a tight coupling between synaptic growth and muscle growth (Davis and Bezprozvanny 2001). In vivo imaging of the Drosophila NMJ with a postsynaptic GFP-tagged Shaker-CD8 chimera has demonstrated that the addition of synaptic boutons at the NMJ is an active process occurring throughout larval development (Zito et al. 1999). Retraction of synaptic area and the removal of boutons were not documented in these experiments, although the rate at which this postsynaptic marker protein disassembles might mask rapid presynaptic disassembly events.

It has been recently shown that rapid disassembly of axonal branches occurs at the Drosophila NMJ during 
development (Eaton et al. 2002). Based on the earlier observations at the frog NMJ that local presynaptic branch retraction led to a loss of opposition of pre- and postsynaptic markers (synaptic footprints; Wernig et al. 1980), an assay was developed to identify synaptic footprints in Drosophila using antibodies to the presynaptic marker synapsin and the PSD95 homolog discs-large. Using this assay, it was shown that footprints occur throughout development and that the percentage of synapses with footprints was increased during the most rapid phases of synaptic growth. This suggests two things, first, that growth at the Drosophila NMJ is a balance of bouton addition and retraction and, second, that the amount of elimination that occurs at the NMJ is regulated developmentally. Importantly, footprints often were restricted to individual branches or regions of branches suggesting that the events themselves are local and presumably do not result in the complete elimination of the input. Therefore, models of elimination from the mammalian NMJ using asynchronous activity probably do not apply to the elimination of a single branch within a single Drosophila NMJ. It is possible, though, that the synapse as a whole is supported by a limited amount of muscle-supplied trophic support and that when synaptic growth exceeds this level, a program of elimination is activated to bring the size of the NMJ back in line with the level of support. It is also possible that competition exists between branches of the same junction, although the observation that multiple branches retract within the same NMJ does not support this interpretation.

\section{How do synapses disassemble?}

\section{Local versus cell-wide synapse disassembly}

The local remodeling of synaptic connections (i.e., synapses) without the complete removal of an input is a prominent feature of plasticity and may be associated with the rapid formation or elimination of dendritic spines (Dailey and Smith 1996; Engert and Bonhoeffer 1999; Maletic-Savatic et al. 1999; Toni et al. 1999; Lendvai et al. 2000; Grutzendler et al. 2002; Trachtenberg et al. 2002; Dunaevsky and Mason 2003), as well as changes in axonal or dendritic arborization (Harris and Woolsey 1981; Greenough et al. 1985; Purves and Hadley 1985; Purves et al. 1986; Petit et al. 1988; O'Rourke and Fraser 1990; Darian-Smith and Gilbert 1994; Baker and Van Pelt 1997; Rajan and Cline 1998; Lom and Cohen-Cory 1999; Rajan et al. 1999; Sin et al. 2002). Despite the progress made recently in understanding the dynamics and driving forces behind these events, there is still little known about the downstream signals that instruct a synapse where and when to assemble or disassemble.

Recent in vivo imaging studies have provided strong evidence that synaptic elimination events are localized both spatially and temporally. In vivo imaging of dendritic segments within both the barrel cortex and the visual cortex of mice have shown spines disappearing at different places and at different times within the same region of dendrite (Lendvai et al. 2000; Grutzendler et al.
2002; Trachtenberg et al. 2002). A similar in vivo imaging technique of the axonal arborization of retinal ganglion cells within the tadpole visual system has also demonstrated that asynchrony of branch elimination can also occur presynaptically (Cohen-Cory 1999; Sin et al. 2002). At present, although there are strong data correlating new spine formation with enhanced efficacy, it remains unclear whether the loss of a spine or branch is associated with the disassembly of a previously functional active zone. At the vertebrate NMJ the evidence for local elimination of functional active zones is clearer. In vivo imaging of an entire motor unit has revealed asynchrony and spatial heterogeneity in the elimination of functional endplates within a single motor unit (Keller-Peck et al. 2001). Thus, because synapse disassembly can vary both spatially and temporally at the terminals of a single cell in a variety of different systems, these data indicate that synaptic elimination can be regulated locally at the site of disassembly.

Data suggesting the existence of cell-wide programs that influence synapse assembly and disassembly have also been obtained from in vivo imaging of Homer 1cGFP (PSDZip45-GFP) clusters in hippocampal neuronal cultures (Ebihara et al. 2003) and synaptophysin-GFP puncta in presynaptic arbors in hippocampal slice cultures (De Paola et al. 2003). Ebihara and colleagues (2003) imaged PSDZip45-GFP clusters in four distinct dendritic regions within neurons every 24 h over the course of a week and show both assembly and disassembly of clusters. Analysis of five sets of culture preparations showed that correlation of cluster changes within the same cell was significantly higher than the correlation of changes between different cells. In vivo imaging of synaptophysin-GFP puncta in hippocampal slice cultures have also demonstrated that both cAMP and receptor activation can elevate numbers of puncta forming and disappearing within $1 \mathrm{~d}$ (De Paola et al. 2003). Interestingly, the gains equal the losses of synaptophysin-GFP puncta suggesting that in these mature cultures the increase in dynamics does not lead to a net increase or decrease of synaptic size. These data support the existence of cell-wide programs that are able to bias the cell towards synaptogenesis or disassembly. Although the mechanisms that bias a cell toward enhanced remodeling are unclear, they may relate to developmental phenomena such as the existence of critical periods for synaptic rearrangement.

\section{Sequence of synapse disassembly}

Data from the mammalian NMJ and from the cerebellum support the model that elimination is mediated via the postsynaptic cell. This does not necessarily mean that the disassembly process itself begins in the postsynaptic cell. In fact, most data supports presynaptic disassembly preceding postsynaptic disassembly. At the mammalian NMJ, recent live-imaging data has clearly demonstrated that retraction of presynaptic membrane can precede the loss of postsynaptic receptors (Walsh and Lichtman 2003). It should be noted though that previous work from the same laboratory supported the hypothesis 
that disassembly of the postsynaptic apparatus preceded the withdrawal of the axon terminal (Balice-Gordon et al. 1993; Colman et al. 1997), suggesting that at the vertebrate NMJ perhaps elimination can initiate either preor postsynaptically. At the Drosophila NMJ, experimental disruption of the dynactin/dynein motor complex by transgenic expression presynaptically of a dominantnegative P150/Glued (DN-Glued) increases the frequency of elimination events (Eaton et al. 2002). Subsequent immunolocalization studies in these animals suggest that the dissolution of the postsynaptic specialization follows presynaptic disassembly, based on the observations that the retraction of the presynaptic markers synapsin and futsch, a synaptic microtubule-binding protein, precedes the elimination of Discs-large immunoreactivity and GluR clusters. In addition, there is no observed change in quantal size in animals expressing DN-Glued despite severely impaired release supporting the existence of normal receptor clusters at poisoned synapses. These results present an initial blueprint for the stepwise disassembly of synaptic contacts, which begins with the disassembly of the presynaptic cytoskeleton, removal of synaptic vesicle release machinery, retraction of presynaptic membrane, disassembly of postsynaptic receptor clusters, and finally dissolution of postsynaptic scaffolding structures. Because presynaptic innervation is thought to provide instructive and maintenance functions for postsynaptic structures (Saitoe et al. 2001; Sanes and Lichtman 2001), it is still unclear from these results whether postsynaptic disassembly is a directed process or the result of the loss of some maintenance factor(s) normally provided by the motorneuron.

\section{Mechanisms of synapse disassembly}

Theoretically, synapse disassembly could be achieved by loss of a subcellular mechanism that maintains the synapse or could be due to mechanisms that actively drive the disassembly of the synapse. There is ample evidence at both central and peripheral synapses that trophic factors participate in synapse maintenance (McAllister et al. 1999; Huang and Reichardt 2001). Specifically, impairment of either TrkB signaling to the muscle or NT-4 production within the muscle promotes synapse disassembly at the vertebrate NMJ (Gonzalez et al. 1999; Belluardo et al. 2001). At the Drosophila NMJ, impaired TGF- $\beta$ signaling caused by receptor mutations or impaired retrograde trafficking of the TGF- $\beta$ signal enhances the incidence of synaptic retraction events (Eaton et al. 2002; B. Eaton and G. Davis, unpubl.).

These data might suggest that loss of trophic signaling could account for synapse elimination, perhaps because of a loss of synaptic maintenance. However, the speed at which synapse disassembly occurs can be more rapid, in many cases, than the normal rates of protein turnover at the synapse indicating that passive disassembly cannot account for all synapse disassembly. For example, the half-life of AMPA receptors at a central synapse has been measured to be $18-23 \mathrm{~h}$, and the half-life of NR2 is $16 \mathrm{~h}$ (Huh and Wenthold 1999). Yet, live-imaging studies have demonstrated that AMPA receptor-containing synapses can be eliminated as quickly as $90 \mathrm{~min}$ and dendritic spines have been observed to be eliminated in $<1 \mathrm{~d}$ (Okabe et al. 2001; Grutzendler et al. 2002; Trachtenberg et al. 2002). At both central and peripheral synapses, the rates of transmitter receptor trafficking are influenced by preand postsynaptic activity and an increasingly well-understood array of signaling molecules (Akaaboune et al. 1999; Chen et al. 2000; Esteban et al. 2003). These recent data point to the existence of mechanisms that can regulate the assembly and disassembly of synaptic connections. At the vertebrate NMJ, the existence of a "punishment" signal or a "synaptotoxin" has long been hypothesized to participate in the induction of synaptic input elimination (Nguyen and Lichtman 1996). Although these putative factors that would drive synaptic disassembly remain to be identified, they may be related to the factors that modulate the rate of protein turnover at the synapse.

One potential mechanism of synapse disassembly could involve the targeted degradation of synaptic components via ubiquitin-mediated degradation, a process that has been demonstrated to be involved in the degradation of proteins and protein complexes in many systems (von Arnim 2001; Stahl and Barbieri 2002). For example, evidence from Caenorhabditis elegans suggests that transgenic elevation of ubiquitin levels postsynaptically results in a reduction in glutamate receptor density at the synapse (Burbea et al. 2002). Also, recent studies of input elimination during metamorphosis in Drosophila show that disruption of the ubiquitin-proteosome system blocks axon pruning (Watts et al. 2003). These data support the possibility that altering the rates of degradation or trafficking of synaptic components could modulate synapse stability or maintenance.

The disassembly of large protein complexes is common throughout biology. Perhaps insight into the molecular mechanisms that drive synapse disassembly can be gleaned from examples of junctional disassembly in other cell biological contexts. A potentially relevant process is the disassembly of adherens junctions (AJs) in epithelial cells. AJs are specialized forms of cadherinbased adhesive contacts that are important for tissue organization including within the nervous system. Cadherins are type I transmembrane proteins that form a complex with cytosolic catenins, which, in turn, provide anchorage for the actin cytoskeleton resulting in the formation of stable sites of contact between cells (Yap et al. 1997). In epithelial cells, AJs are disassembled in response to hepatocyte growth factor/scatter factor (HGF/ $\mathrm{SF}$ ) via the activation of MAP kinase and PI 3-kinase (Potempa and Ridley 1998). The process of AJ disassembly is thought to include the internalization of E-cadherin via an ARF6-regulated membrane trafficking event resulting in a decrease in cell-to-cell adhesion and the loss of AJ integrity (Palacios et al. 2001). Perhaps the local activation of membrane trafficking events leading to the down-regulation of cell adhesion will also play an important role in synaptic disassembly as well. It is intriguing that EM analysis of retraction events in Dro- 

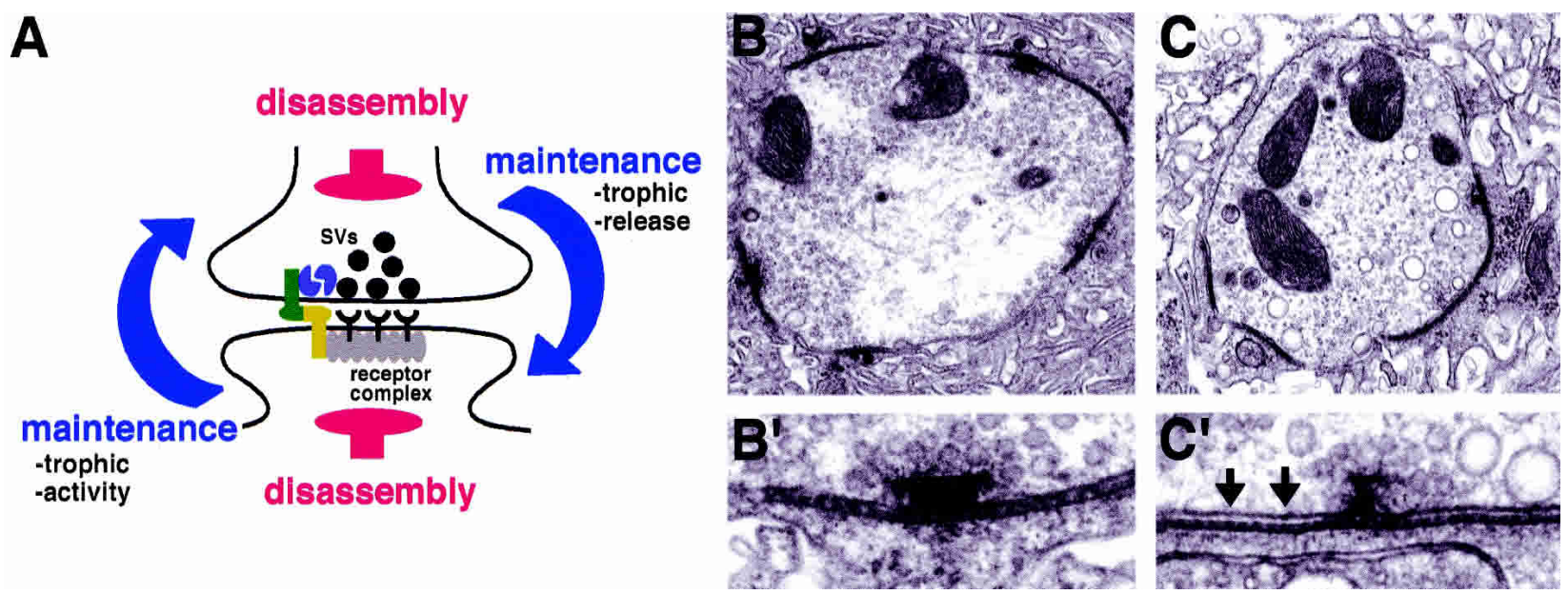

Figure 1. The disassembly of functional active zones. (A) Synaptic elimination is a local event involving the directed disassembly of complex macromolecular machines. Disassembly would necessarily involve the removal of release machinery, receptor complexes, synapse-spanning protein complexes, and pre- and postsynaptic scaffolding proteins. Synapse stability is maintained by trophic factors such as neurotrophins released from both the pre- and postsynaptic cell and may be regulated by additional factors including muscle activity. (B) Ultrastructural analysis of a wild-type bouton at the Drosophila NMJ. ( $\left.B^{\prime}\right)$ Close-up of wild-type active zone demonstrating the close opposition of the pre- and postsynaptic membranes within the EM dense region surrounding the T-bar, a morphological marker of active zones in Drosophila. (C) Ultrastructural analysis of a bouton undergoing disassembly at the Drosophila NMJ (Eaton et al. 2002). Note the increase in vacuolarization, potentially indicating the internalization of plasma membrane. ( $\left.C^{\prime}\right)$ Close-up of an active zone at a synapse undergoing disassembly. Arrows indicate the "unzippering" of pre- and postsynaptic membranes suggesting a loss of adhesion at the active zone.

sophila demonstrate a loss of adhesion between pre- and postsynaptic membranes within the active zone, a specialized site of cell-to-cell contact within the bouton (Fig. $\left.1 \mathrm{~B}^{\prime}, \mathrm{C}^{\prime}\right)$.

As discussed above, a prominent feature of synapse elimination in all systems is the localized disassembly of synaptic complexes. Whether the removal of trophic support or the active disassembly of the synapse or both drives synapse elimination, it remains to be determined how these mechanisms are locally specified. It is interesting to speculate that precise regulation could be achieved by requiring that multiple signaling systems simultaneously converge to eliminate a synaptic connection.

\section{Acknowledgments}

We thank Kurt Marek and Jan Pielage for critical evaluations of preliminary versions of this manuscript. This work was supported by an NSF grant to G.W.D. B.A.E. is supported by an NRSA postdoctoral fellowship (F32 NS42533).

\section{References}

Aiba, A., Kano, M., Chen, C., Stanton, M.E., Fox, G.D., Herrup, K., Zwingman, T.A., and Tonegawa, S. 1994. Deficient cerebellar long-term depression and impaired motor learning in mGluR1 mutant mice. Cell 79: 377-388.

Akaaboune, M., Culican, S.M., Turney, S.G., and Lichtman, J.W. 1999. Rapid and reversible effects of activity on acetylcholine receptor density at the neuromuscular junction in vivo. Science 286: 503-507.
Bailey, C.H. and Kandel, E.R. 1993. Structural changes accompanying memory storage. Annu. Rev. Physiol. 55: 397-426.

Baker, R.E. and Van Pelt, J. 1997. Cocultured, but not isolated, cortical explants display normal dendritic development: A long-term quantitative study. Brain Res. Dev. Brain Res. 98: 21-29.

Balice-Gordon, R.J. and Lichtman, J.W. 1994. Long-term synapse loss induced by focal blockade of postsynaptic receptors. Nature 372: 519-524.

Balice-Gordon, R.J., Chua, C.K., Nelson, C.C., and Lichtman, J.W. 1993. Gradual loss of synaptic cartels precedes axon withdrawal at developing neuromuscular junctions. Neuron 11: 801-815.

Barry, J.A. and Ribchester, R.R. 1995. Persistent polyneuronal innervation in partially denervated rat muscle after reinnervation and recovery from prolonged nerve conduction block. J. Neurosci. 15: 6327-6339.

Belluardo, N., Westerblad, H., Mudo, G,. Casabona, A., Bruton, J., Caniglia, G., Pastoris, O., Grassi, F., and Ibanez, C.F. 2001. Neuromuscular junction disassembly and muscle fatigue in mice lacking neurotrophin-4. Mol. Cell. Neurosci. 18: 56-67.

Buffelli, M., Busetto, Cangiano, L., and Cangiano, A. 2002. Perinatal switch from synchronous to asynchronous activity of motoneurons: Link with synapse elimination. Proc. Nat1. Acad. Sci. 99: 13200-13205.

Burbea, M., Dreier, L., Dittman, J.S., Grunwald, M.E., and Kaplan, J.M. 2002. Ubiquitin and AP180 regulate the abundance of GLR-1 glutamate receptors at postsynaptic elements in C. elegans. Neuron 35: 107-120.

Chen, C., Kano, M., Abeliovich, A., Chen, L., Bao, S., Kim, J.J., Hashimoto, K., Thompson, R.F., and Tonegawa, S. 1995. Impaired motor coordination correlates with persistent multiple climbing fiber innervation in PKC $\gamma$ mutant mice. Cell 83: $1233-1242$.

Chen, L., Chetkovich, D.M., Petralia, R.S., Sweeney, N.T., Ka- 
wasaki, Y., Wenthold, R.J., Bredt, D.S., and Nicoll, R.A. 2000. Stargazin regulates synaptic targeting of AMPA receptors by two distinct mechanisms. Nature 408: 936-943.

Cline, H.T. 2001. Dendritic arbor development and synaptogenesis. Curr. Opin. Neurobiol. 11: 118-126.

Cohen-Cory, S. 1999. BDNF modulates, but does not mediate, activity-dependent branching and remodeling of optic axon arbors in vivo. J. Neurosci. 19: 9996-10003.

. 2002. The developing synapse: Construction and modulation of synaptic structures and circuits. Science 298: 770776.

Colman, H., Nabekura, J., and Lichtman, J.W. 1997. Alterations in synaptic strength preceding axon withdrawal. Science 275: 356-361.

Conquet, F., Bashir, Z.I., Davies, C.H., Daniel, H., Ferraguti, F., Bordi, F., Franz-Bacon, K., Reggiani, A., Matarese, V., Conde, F., et al. 1994. Motor deficit and impairment of synaptic plasticity in mice lacking mGluR1. Nature 372: 237-243.

Costanzo, E.M., Barry, J.A., and Ribchester, R.R. 2000. Competition at silent synapses in reinnervated skeletal muscle. Nat. Neurosci. 3: 694-700.

Crepel, F. and Mariani, J. 1976. Multiple innervation of Purkinje cells by climbing fibers in the cerebellum of the Weaver Mutant Mouse. J. Neurobiol. 7: 579-582.

Crepel, F., Delhaye-Bouchaud, N., Guastavino, J.M., and Sampaio, I. 1980. Multiple innervation of cerebellar Purkinje cells by climbing fibres in staggerer mutant mouse. Nature 283: 483-484.

Dailey, M.E. and Smith, S.J. 1996. The dynamics of dendritic structure in developing hippocampal slices. I. Neurosci. 16: 2983-2994.

Darian-Smith, C. and Gilbert, C.D. 1994. Axonal sprouting accompanies functional reorganization in adult cat striate cortex. Nature 368: 737-740.

Davis, G.W. and Bezprozvanny, I. 2001. Maintaining the stability of neural function: A homeostatic hypothesis. Annu. Rev. Physiol. 63: 847-869.

De Paola, V., Arber, S., and Caroni, P. 2003. AMPA receptors regulate dynamic equilibrium of presynaptic terminals in mature hippocampal networks. Nat. Neurosci. 6: 491-500.

Dunaevsky, A. and Mason, C.A. 2003. Spine motility: A means towards an end? Trends Neurosci, 26: 155-160.

Duxson, M.J. and Vrbova, G. 1985. Inhibition of acetylcholinesterase accelerates axon terminal withdrawal at the developing rat neuromuscular junction. J. Neurocytol. 14: 337363.

Eaton, B.A., Fetter, R.D., and Davis, G.W. 2002. Dynactin is necessary for synapse stabilization. Neuron 34: 729-741.

Ebihara, T., Kawabata, I., Usui, S, Sobue, K., and Okabe, S. 2003. Synchronized formation and remodeling of postsynaptic densities: Long-term visualization of hippocampal neurons expressing postsynaptic density proteins tagged with green fluorescent protein. J. Neurosci. 23: 2170-2181.

Engert, F. and Bonhoeffer, T. 1999. Dendritic spine changes associated with hippocampal long-term synaptic plasticity. Nature 399: 66-70.

Esteban, J.A., Shi, S.H., Wilson, C., Nuriya, M., Huganir, R.L., and Malinow, R. 2003. PKA phosphorylation of AMPA receptor subunits controls synaptic trafficking underlying plasticity. Nat. Neurosci. 6: 136-143.

Gonzalez, M., Ruggiero, F.P., Chang, Q., Shi, Y.J., Rich, M.M., Kraner, S., and Balice-Gordon, R.J. 1999. Disruption of Trkbmediated signaling induces disassembly of postsynaptic receptor clusters at neuromuscular junctions. Neuron 24: 567583.

Greenough, W.T., Larson, J.R., and Withers, G.S. 1985. Effects of unilateral and bilateral training in a reaching task on dendritic branching of neurons in the rat motor-sensory forelimb cortex. Behav. Neural Biol. 44: 301-314.

Grutzendler, J., Kasthuri, N., and Gan, W.B. 2002. Long-term dendritic spine stability in the adult cortex. Nature 420: 812-816.

Harris, R.M. and Woolsey, T.A. 1981. Dendritic plasticity in mouse barrel cortex following postnatal vibrissa follicle damage. J. Comp. Neurol. 196: 357-376.

Huang, E.J. and Reichardt, L.F. 2001. Neurotrophins: Roles in neuronal development and function. Annu. Rev. Neurosci. 24: $677-736$

Huh, K.H. and Wenthold, R.J. 1999. Turnover analysis of glutamate receptors identifies a rapidly degraded pool of the $\mathrm{N}$ methyl-D-aspartate receptor subunit, NR1, in cultured cerebellar granule cells. J. Biol. Chem. 274: 151-157.

Ichise, T., Kano, M., Hashimoto, K., Yanagihara, D., Nakao, K., Shigemoto, R., Katsuki, M., and Aiba, A. 2000. mGluR1 in cerebellar Purkinje cells essential for long-term depression, synapse elimination, and motor coordination. Science 288: 1832-1835.

Ito, M. 1984. The modifiable neuronal network of the cerebellum. Jpn. J. Physiol. 34: 781-792.

Kano, M., Hashimoto, K., Chen, C., Abeliovich, A., Aiba, A., Kurihara, H., Watanabe, M., Inoue, Y., and Tonegawa, S. 1995. Impaired synapse elimination during cerebellar development in PKC $\gamma$ mutant mice. Cell 83: 1223-1231.

Kano, M., Hashimoto, K., Kurihara, H., Watanabe, M., Inoue, Y., Aiba, A., and Tonegawa, S. 1997. Persistent multiple climbing fiber innervation of cerebellar Purkinje cells in mice lacking mGluR1. Neuron 18: 71-79.

Keller-Peck, C.R., Walsh, M.K., Gan, W.B., Feng, G., Sanes, J.R., and Lichtman, J.W. 2001. Asynchronous synapse elimination in neonatal motor units: Studies using GFP transgenic mice. Neuron 31: 381-394.

Keshishian, H., Broadie, K., Chiba, A., and Bate, M. 1996. The Drosophila neuromuscular junction: A model system for studying synaptic development and function. Annu. Rev. Neurosci. 19: 545-575.

Kim, D., Jun, K.S., Lee, S.B., Kang, N.G., Min, D.S., Kim, Y.H., Ryu, S.H., Suh, P.G., and Shin, H.S. 1997. Phospholipase C isozymes selectively couple to specific neurotransmitter receptors. Nature 389: 290-293.

Kuffler, D., Thompson, W., and Jansen, J.K. 1977. The elimination of synapses in multiply-innervated skeletal muscle fibres of the rat: Dependence on distance between end-plates. Brain Res. 138: 353-358.

Lee, T., Marticke, S., Sung, C., Robinow, S., and Luo, L. 2000 Cell-autonomous requirement of the USP/EcR-B ecdysone receptor for mushroom body neuronal remodeling in Drosophila. Neuron 28: 807-818.

Lendvai, B., Stern, E., Chen, B., and Svoboda, K. 2000. Experience-dependent plasticity of dendritic spines in the developing rat barrel cortex in vivo. Nature 404: 876-881.

Lichtman, J.W. and Colman, H. 2000. Synapse elimination and indelible memory. Neuron 25: 269-278

Lichtman, J.W. and Purves, D. 1980. The elimination of redundant preganglionic innervation to hamster sympathetic ganglion cells in early post-natal life. J. Physiol. 301: 213-228.

Lom, B. and Cohen-Cory, S. 1999. Brain-derived neurotrophic factor differentially regulates retinal ganglion cell dendritic and axonal arborization in vivo. J. Neurosci. 19: 9928-9938.

Luo, L. 2000. Rho GTPases in neuronal morphogenesis. Nat. Rev. Neurosci. 1: 173-80.

Maletic-Savatic, M., Malinow, R., and Svoboda, K. 1999. Rapid dendritic morphogenesis in CA1 hippocampal dendrites in- 
duced by synaptic activity. Science 283: 1923-1927.

Mason, C.A. and Gregory, E. 1984. Postnatal maturation of cerebellar mossy and climbing fibers: Transient expression of dual features on single axons. J. Neurosci. 4: 1715-1735.

Mason, C.A., Christakos, S., and Catalano, S.M. 1990. Early climbing fiber interactions with Purkinje cells in the postnatal mouse cerebellum. J. Comp. Neurol. 297: 77-90.

McAllister, A.K., Katz, L.C., and Lo, D.C. 1999. Neurotrophins and synaptic plasticity. Annu. Rev. Neurosci. 22: 295-318.

Nguyen, Q.T. and Lichtman, J.W. 1996. Mechanism of synapse disassembly at the developing neuromuscular junction. Curr. Opin. Neurobiol. 6: 104-112.

Offermanns, S., Hashimoto, K., Watanabe, M., Sun, W., Kurihara, H., Thompson, R.F., Inoue, Y., Kano, M., and Simon, M.I. 1997. Impaired motor coordination and persistent multiple climbing fiber innervation of cerebellar Purkinje cells in mice lacking Gaq. Proc. Natl. Acad. Sci. 94: 1408914094.

Okabe, S., Miwa, A., and Okado, H. 2001. Spine formation and correlated assembly of presynaptic and postsynaptic molecules. J. Neurosci. 21: 6105-6114.

O'Rourke, N.A. and Fraser, S.E. 1990. Dynamic changes in optic fiber terminal arbors lead to retinotopic map formation: An in vivo confocal microscopic study. Neuron 5: 159-171.

Palacios, F., Price, L., Schweitzer, J., Collard, J.G., and D'SouzaSchorey, C. 2001. An essential role for ARF6-regulated membrane traffic in adherens junction turnover and epithelial cell migration. EMBO I. 20: 4973-4986.

Personius, K.E. and Balice-Gordon, R.J. 2001. Loss of correlated motor neuron activity during synaptic competition at developing neuromuscular synapses. Neuron 31: 395-408.

Petit, T.L., LeBoutillier, J.C., Gregorio, A., and Libstug, H. 1988. The pattern of dendritic development in the cerebral cortex of the rat. Brain Res. 469: 209-219.

Potempa, S. and Ridley, A.J. 1998. Activation of both MAP kinase and phosphatidylinositide 3-kinase by Ras is required for hepatocyte growth factor/scatter factor-induced adherens junction disassembly. Mol. Biol. Cell 9: 2185-2200.

Pun, S., Sigrist, M., Santos, A.F., Ruegg, M.A., Sanes, J.R., Jessell, T.M., Arber, S., and Caroni, P. 2002. An intrinsic distinction in neuromuscular junction assembly and maintenance in different skeletal muscles. Neuron 34: 357-370.

Purves, D. and Hadley, R.D. 1985. Changes in the dendritic branching of adult mammalian neurons revealed by repeated imaging in situ. Nature 315: 404-406.

Purves, D. and Lichtman, J.W. 1980. Elimination of synapses in the developing nervous system. Science 210: 153-157.

Purves, D., Hadley, R.D., and Voyvodic, J.T. 1986. Dynamic changes in the dendritic geometry of individual neurons visualized over periods of up to three months in the superior cervical ganglion of living mice. J. Neurosci. 6: 1051-1060.

Rajan, I. and Cline, H.T. 1998. Glutamate receptor activity is required for normal development of tectal cell dendrites in vivo. J. Neurosci. 18: 7836-7846.

Rajan, I., Witte, S., and Cline, H.T. 1999. NMDA receptor activity stabilizes presynaptic retinotectal axons and postsynaptic optic tectal cell dendrites in vivo. I. Neurobiol. 38: 357-368.

Saitoe, M., Schwarz, T.L., Umbach, J.A., Gundersen, C.B., and Kidokoro, Y. 2001. Absence of junctional glutamate receptor clusters in Drosophila mutants lacking spontaneous transmitter release. Science 293: 514-517.

Sanes, J.R. and Lichtman, J.W. 1999. Development of the vertebrate neuromuscular junction. Annu. Rev. Neurosci. 22: $389-442$.

- 2001. Induction, assembly, maturation and mainte- nance of a postsynaptic apparatus. Nat. Rev. Neurosci. 2: 791-805.

Scheiffele, P. 2003. Cell-cell signaling during synapse formation in the CNS. Annu. Rev. Neurosci. 26: 485-508 [Epub ahead of print 10.1146/annurev.neuro.26.043002.094940].

Sheng, M. and Kim, M.J. 2002. Postsynaptic signaling and plasticity mechanisms. Science 298: 776-780.

Sheng, M. and Lee, S.H. 2000. Growth of the NMDA receptor industrial complex. Nat. Neurosci. 3: 633-635.

Sin, W.C., Haas, K., Ruthazer, E.S., and Cline., H.T. 2002. Dendrite growth increased by visual activity requires NMDA receptor and Rho GTPases. Nature 419: 475-480.

Sotelo, C. 1975. Anatomical, physiological and biochemical studies of the cerebellum from mutant mice. II. Morphological study of cerebellar cortical neurons and circuits in the weaver mouse. Brain Res. 94: 19-44.

Stahl, P.D. and Barbieri, M.A. 2002. Multivesicular bodies and multivesicular endosomes: The 'ins and outs' of endosomal traffic. Sci. STKE 2002: PE32.

Thach, W.T., Goodkin, H.P., and Keating, J.G. 1992. The cerebellum and the adaptive coordination of movement. Annu. Rev. Neurosci. 15: 403-442.

Thompson, W.J. 1985. Activity and synapse elimination at the neuromuscular junction. Cell. Mol. Neurobiol. 5: 167-182.

Toni, N., Buchs, P.A., Nikonenko, I., Bron, C.R., and Muller, D. 1999. LTP promotes formation of multiple spine synapses between a single axon terminal and a dendrite. Nature 402: 421-425.

Trachtenberg, J.T., Chen, B.E., Knott, G.W., Feng, G., Sanes, J.R., Welker, E., and Svoboda, K. 2002. Long-term in vivo imaging of experience-dependent synaptic plasticity in adult cortex. Nature 420: 788-794.

von Arnim, A.G. 2001. A hitchhiker's guide to the proteasome. SCI STKE 2001: PE2.

Walikonis, R.S., Jensen, O.N., Mann, M., Provance Jr., D.W., Mercer, J.A., and Kennedy, M.B. 2000. Identification of proteins in the postsynaptic density fraction by mass spectrometry. J. Neurosci. 20: 4069-4080.

Walsh, M.K. and Lichtman, J.W. 2003. In vivo time-lapse imaging of synaptic takeover associated with naturally occurring synapse elimination. Neuron 37: 67-73.

Watts, R.J., Hoopfer, E.D., and Luo, L. 2003. Axon pruning during Drosophila metamorphosis. evidence for local degeneration and requirement of the ubiquitin-proteasome system. Neuron 38: 871-885.

Wernig, A., Pecot-Dechavassine, M., and Stover, H. 1980. Sprouting and regression of the nerve at the frog neuromuscular junction in normal conditions and after prolonged paralysis with curare. J. Neurocytol. 9: 278-303.

Yap, A.S., Brieher, W.M., and Gumbiner, B.M. 1997. Molecular and functional analysis of cadherin-based adherens junctions. Annu. Rev. Cell. Dev. Biol. 13: 119-146.

Yuste, R. and Bonhoeffer, T. 2001. Morphological changes in dendritic spines associated with long-term synaptic plasticity. Annu. Rev. Neurosci. 24: 1071-1089.

Zito, K., Parnas, D., Fetter, R.D., Isacoff, E.Y., and Goodman, C.S. 1999. Watching a synapse grow: Noninvasive confocal imaging of synaptic growth in Drosophila. Neuron 22: 719 729 


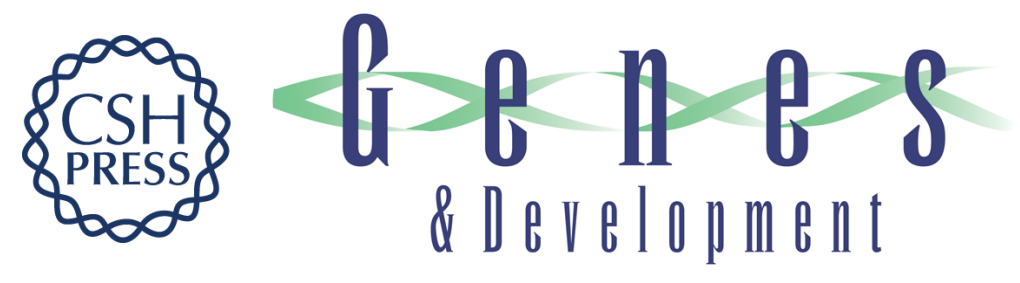

\section{Synapse disassembly}

Benjamin A. Eaton and Graeme W. Davis

Genes Dev. 2003, 17:

Access the most recent version at doi:10.1101/gad.1113703

References This article cites 87 articles, 23 of which can be accessed free at: http://genesdev.cshlp.org/content/17/17/2075.full.html\#ref-list-1

License

Email Alerting Receive free email alerts when new articles cite this article - sign up in the box at the top Service right corner of the article or click here.

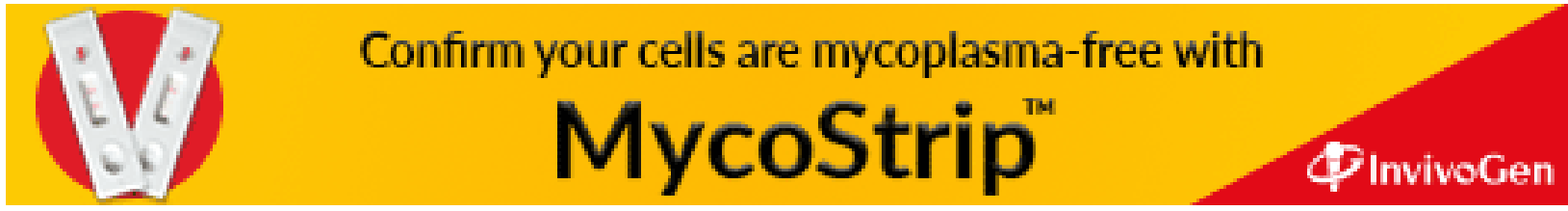

